\title{
Exploring The Experience Of Using Simulation-Games In Project Management Teaching: A Phenomenographic Approach
}

\author{
Jorge Alberto dos Santos \\ Universidade Federal de Viçosa, MG, Brazil \\ Petros Lameras \\ Coventry University, Coventry, UK
}

\begin{abstract}
This research describes how lecturers conceptualize the experience of using simulation-games in the teaching of management, especially project management. The research uses a phenomenographic approach, seeking to explore and categorize teachers' perception variation. The research was carried out with twelve lecturers from three different universities in the United Kingdom. The data was collected using interviews. The data showed that the variation in teachers' description of their relationship with simulation-games in teaching management could be synthesized in a set of four different categories, ranging from simulation-games as "resource to improve the acquisition of content" to simulation-games as "a means to bear resemblance to reality". The main conclusion is that there are two orientations in teachers' approach to simulation-games: on the one hand, there are those who are interested in delivering some kind of learning goals through it. I called this teachers' orientation instrumental. On the other hand, there are those for whom simulation-games promote a special kind of bond in students' relationship which, in turn, help them achieve their learning goals. I called this teachers' orientation engagement.
\end{abstract}

Keywords: Project Management Education, Simulations, games, Phenomenography.

\section{INTRODUCTION}

Teaching is an important and demanding task. Following the tradition of Dewey [1] and Knowles [2,3] in adult education, the purpose of teaching may be seen as an activity to bring personal growth that impacts positively individuals' life [4]. However, the nature and meaning of teaching cannot be understood separately from the concept of learning. Although learning can take place without teaching, the opposite is not true: teaching cannot be conceived without learning. Therefore, teaching should be located into a framework in which learning takes the central role.

To do his/her job, every lecturer needs to employ some kind of method. In this research, the interest lays in how lecturers conceive a special method - the use of simulation or games in their teaching. In this ever-changing technological world, higher education should pay attention to game-based learning [5]. The paper looks especially at how teachers experience the use of simulations and games in management education - and especially in project management education -, researching the relationship of teachers, students and context when they are using these tools. Simulations and games here have a loose meaning, including any activity used in class, which have features of gamification and thereafter will be referred as simulation-games. In short, gamification uses game mechanics to enhance learning, commitment, and the enjoyment of players in a given environment $[6,8]$. The hope is that management education and especially project management education may benefit from it. 
Management education in general and project management education in special has struggled to find new pedagogical strategies to convey more meaningful experience to students. Some authors have stated that project management is "inherently an experiential learning" (p.1) [9] as project management "is about [people] making something complex happen" (p. 201) [10]. Despite that, Pant and Baroudi [11] point out that "project management discipline still appears to place greater emphasis on hard skills at the expense of the softer human skills" (p. 127). Classroom technology has been upgraded constantly, but what misses, according to Wood \& Reiners [12], is a "change to make the material more engaging for students and to provide a sense of immersion" (p. 315). This immersion may also help participants to acquire employability skills, "which include the ability to problem solve, work as part of a team and manage time effectively" (p. 38) [13]. Employability skills are the most important factor when recruiting graduates [13]. Simulation-games can play a role in this direction.

The main question of the research is: how do teachers conceptualize simulation-games in their teaching experience? Simulation-games here will be defined in a very broad sense, meaning any kind of experience that engages students in relating to the content of the discipline cooperatively or competitively. The answer to this question will be responded in a phenomenographic perspective.

The structure of this paper is as follow. Firstly, the literature is revisited in three basic areas: firstly, what constitute the teaching and learning experience; secondly, the role of simulation and games in management education and, finally, how simulation and games may be important in one specific area of management education: project management. After that, the fundamentals of phenomenography are revisited. Following, the data is described and analysed and finally, discussion and conclusion are presented.

\section{LITERATURE REVIEW}

\section{The Experience of Teaching and Learning}

The experience of teaching has been researched from a varied of perspectives. In this paper, the phenomenon is inspired by a holistic and relational model called the Constitutionalist Experience to Teaching and Learning [14]. This model originated from Mitzel's concepts called the $3 \mathrm{P}$ model of teaching and learning (Presage - Process - Product). Through interaction represented by learning activities or tasks - teachers and students engage in a process phase, in which is expected an outcome represented by a development in what students can demonstrate they have taken out from the teaching and learning experience. It is implicitly expected that students have acquired some new content or skills, which would not be possible without taking part in the experience. Prosser and Trigwell conclude that three main elements and their relationship are important to understand a teaching and learning experience: a) teachers (and their concepts and approaches to teaching); b) students (and their concepts and approaches to learning) and; c) context.

Firstly, the thoughts and beliefs teachers bring to the classroom are considered important as teachers have the power to choose the methods and tools they are going to use to mediate the interaction. Therefore, understanding the inner world of thoughts and emotions of teachers may lead to understand the outer world of their behaviour [15].

In respect to teachers' thought of teaching, phenomenographic studies have greatly contributed to clarify what teacher's conceptions are. Trigwell et al. [16], for example, identified five qualitatively different ways in which teachers approach teaching. These were as follows: a) a teacher-focused strategy with the intention of transmitting information to students; with a focus on facts and skills; b) a teacher-focused strategy with the intention that 
students acquire the concepts of the discipline; c) a teacher/student interaction strategy with the intention that students acquire the concepts of the discipline. The distinctive feature of this approach is the active engagement of students in the teaching-learning process; d) a studentfocused strategy aimed at student developing their conceptions; e) and finally, a studentfocused strategy aimed at students changing their conceptions, in which teachers acknowledge students themselves have to re-construct their knowledge to produce a new world view or conception. Trigwell et al.'s categorization is congruent with other works [17]; [18]; [19]; [20]; [21]; [22], [23] which also demonstrate that teacher's approach to teaching could be categorized in an array of ways ranging from a limited conception of information transmition to a more or less complete approach of students' conception change helpers.

Secondly, research also points to the influence of students' concepts and approaches to learning, individual learning styles [24] and personality traits [25]; [26] and how these features affect their achievements. Despite that, it is unquestionable that the unidirectional-lecture-drill-test method continues to be the most common approach used by teachers. Nevertheless, schools would benefit from using more differentiated instruction strategies to meet the needs of students. It is a fact that students nowadays have access to information much easier than ever, making them, for example, free to progress in the pace they feel more comfortable. Therefore, schools should offer student-centred methods to engage students in learning.

Finally, the inclusion of context in our framework is in tune with another set of studies, which contend that, the environment (context, situation) and the relationship between learners and their environment is a special feature that influences student outcomes. This view derives from the work of Lave and Wenger [27-28] who proclaimed that the social relations of newcomers and old timers within communities of practice is responsible for transformation in the way apprentices construct the general idea of what constitutes the practice of a community. As Fox [29] adds "situated learning theory (SLT) is distinctive because it perceives learning to be a socially relational rather than a mentalist process" (p. 727).

\section{Simulations as situated educational tools}

There is much discussion about terminology in the field of simulation and games. Terms like experiential, organized play, prescribed rules, competition, fun and others are referred to when considering the definition of these activities. Some definitions may even mix these two activities. According to Bates [30], for instance, "simulations are games that seek to emulate the real-world operating conditions" (p. 9). As the field evolves, though, terminology begins to be more distinctive although still confusing. In this paper, the term used is simulation-games. Some authors stress the abstract and ontological characteristics of simulations [31], while others refer to the dynamics of the relationships and the authentic causal processes embedded in them [32].

The simplest definition of simulation is found in Robinson's book [33]: simulation is "an imitation of a system" (p. 2). In this sense, any miniature or larger model of something is a simulation. These examples are called static simulations. A more appropriate definition in the case of this research is that of Kapp et al. [34]: "simulation is a realistic, controlled-risk environment where learners can practice behaviours and experience the impact of decisions" (p. 58). This kind of simulation involves the passing of time and it is called dynamic simulations. In summary, simulations serve well the purpose of management education, especially project management education - a relationship between activities when a goal is chased. 


\section{What is a project and what is project management?}

According to the Project Management Body of Knowledge [35] a project is a "temporary endeavour undertaken to create a unique product, service, or result" (p. 5). This definition has two distinctive characteristics. Firstly, the outcome must be clearly defined; leaving no doubt that the objective should be achieved at some point in time. Turner [36] adds that projects must deliver "beneficial change", that is, the project is not done for its own sake; instead one should expect the project "to satisfy some purpose or produce some benefit" (p. 5). Secondly, although two distinctive projects may have very similar outcome descriptions, "no two projects are ever exactly alike; even a repeated project will differ from its predecessor in one or more commercial, administrative or physical aspects." (p.1) [37]. Additionally, the process of achieving the outcome is resource consuming, being resources defined as some kind of material or simply time.

Project management may be defined as "both science and art to planning, organizing, implementing, leading, and controlling the work of a project to meet the goals and objectives of the organization" (p. 9) [38]. In this sense, project management encapsulates the definition of management into a project-based scenario. It is a social-technical endeavour [39]. The technical side of the project management deals with the logical and calculated aspects of the project: scope, schedules, resource allocation, budgets and reports. The social side of the project management deals with the communication process, integrating subjects like leadership, teamwork, negotiation, politics and stakeholders' expectations. The client, for example, may be uncertain or may have difficult to describe his expectation [40]. No matter what the definition is, the management of the project is crucial to determine the success or the failure of the project outcome [41].

Nowadays, project management is a distinctive discipline in a curriculum, especially in management and engineering education. Teaching project management is difficult because it encapsulates many other disciplines. As put by Martin [10], "project management is about making something complex happen (on time, with budget and to specification) through other people, which is a fundamental prerogative of management in general" (p. 201). Moreover, project management includes all the major functions of management (planning, organizing, directing and controlling) and many of the challenges a manager encounters in his daily operation (decision making, motivating people, assessing risks, etc.). Invariably, projects demand teams which must collaborate albeit they may be spread geographically [42].

In summary, from a management perspective, a project manager has to deliver something that meets others' expectations within a defined time and within a determined budget, using limited resources.

According to some authors [37, 43]; project management is growing in importance in industries and business of all kinds. That makes project management education a distinctive and important discipline in the programme of many courses and relevant to the education of many kinds of professionals both from the private and the public sector: engineers, managers, administrators and others.

Furthermore, project management education is a widespread area, with many topics to be covered and interconnection with many different disciplines. Moreover, project management education should stress the necessity of teamwork in any kind of project, consider the conflicting necessities of many stakeholders and balance the trade-offs of cost, time and quality. 


\section{Teaching with Project Management Simulations}

To deal with the complexity of learning project management, some project management educators have trusted in project management simulations. Simulations have been used in project management education since long. In theirs 1986' paper, Rounds et alli. [44] describe the development of a simplified microcomputer programme which simulated the progress and project reporting structure of an industrial construction project. The users set up the programme specifying "the desired type, frequency, and detail of reports as well as the intensity of predefined problems that the program introduces to disturb the project" (p. 272). The program was written in FORTRAN and run under the MS-DOS operational system. The main objective of the programme was to strength the project management skills of participants.

Simulations can be thought as a natural though controlled way of putting students into real situations. However, using simulations to teach any discipline entails many challenges. From the start, the challenge is to find the suitable simulation to pick. De Freitas \& Martin [68] offer a four-dimensional framework which may help tutors to evaluate the potential of using games and simulation-based learning in their practices, based on the following dimensions: context, attributes of the particular learner or learner group, the internal representational world of the game or simulation and, finally, the processes of learning. Nevertheless, the authors recognized that the framework needs improving "both as an analytical tool for researchers and as a pragmatic tool for practitioners" (p. 23).

Having chosen the specific simulation to be used, Egenfeldt-Nielson [45] presents another set of challenges: learning environments, personal learning factors and learning outcomes. Learning environments are problematic because schools or learning spaces in general are prepared to more traditional activities of learning. Simulations ideally need its own space to be run. Personal learning factors raise very intriguing questions. One, for instance, is the suitability of games and simulations related to the academic ability of the student. Are games and simulations more suitable to less academic skilled students or to high academic skilled ones? [45]. Finally, another question is about what games and simulations can do in terms of learning outcomes and how can the learning effect of games and simulations be measured?

Therefore, teaching and learning project management is a massive undertaking. Many authors $[9,46,47,48]$ have stated the inadequacy of traditional methods to undertake this endeavour. Telukunta et al. [9], for instance, argue that there is an inadequacy of purpose and method in project management education. While project management is inherently an experiential activity, most project management education strategies are based on sage on the stage methods. Bell's work [48] confirms that "lectures appear to be the predominant method of teaching" (p. 221) in project management. Nevertheless, Telukunta et al. [9] defends that project management education requires an environment "where a learner can act as a project manager ... without the costs and risks associated with an unsuccessful project delivery" (p. 1). They propose simulations as one adequate tool to deliver that. Similarly, Bonazzi et al. [47] state that "project management is a discipline that requires knowledge and reflective practice that allows players to lead the project team in an emergent way" (p. 492).

Weterman et al. [46] alert that business simulations alone may not be an effective pedagogy for teaching terminology, factual knowledge, basic concepts, or principles in project management education; and that these basics can be delivered by lectures. Nevertheless, as Caulfield et al. [49] put it, even if simulation-games are not sufficient to learn project management, they are, definitely, welcomed in project management education. 


\section{METHODOLOGY}

This research uses a phenomenographic approach [50], seeking to explore and categorize the variation in perception of teacher's conception of simulation and games environments in management education. Phenomenography has its appeal for at least two reasons. Firstly, as Cousin [51] put it, "phenomenography enables the researcher to identify the range of different ways in which people understand and experience the same thing" (p. 183). As argued by [52], having knowledge about current understandings is likely to make educational development more focused and effective.

Another point is that phenomenography does not aim for correct or incorrect views of the world and is not interested in classifying some experiences as more significant than others. The aim of phenomenography is not "to classify people, nor is it to compare groups, to explain, to predict, nor to make fair or unfair judgments of people" [53]. Each experience is considered legitimate in its own right and should be considered equally in comparison to any other experience.

Therefore, in this study, there is not a correct answer to the question "how did you experience the management simulation?" Whatever is the answer, there will still be interest in mapping and understanding the relationship between the object of experience and the participants' particular way of thinking. Concluding, Marton [53] asserts that "If we are interested in how people think about, then we have to investigate this very problem because the answer cannot be derived either from what we know ...about the general properties of the human mind ... (p. 178) [53].

\section{Fundamentals of Phenomenography}

The first concept that is important to take note of in phenomenography is the concept of intentionality. Intentionality is the phenomenological principle "denoting that consciousness must be understood in terms of what a subject is aware of in being aware of something" (p. 106) [54]. Intentionality is the notion that all that is "psychic" refers to something that is beyond itself (p. 84) [50]. In this study, intentionality was understood as teacher's choice [ or not ] to use simulation-games in their classes.

This "way of experiencing" is the 'what' aspect of experiencing. However, experiencing involves also to "experience something in a way". This is the 'how' aspect of experiencing. Taking the verb to learn as an example Marton and Booth [50] state that "to learn' has to have two objects: ... [the what and the how]; the former referring to the type of capabilities the learner is trying to master ... the latter referring to the experience of the way in which the act of learning is carried out" (p. 84). In their classes, management teachers always should choose what to approach and how to approach.

Carrying out a phenomenographic study must consider three types of entities: the researcher, the phenomenon of study and the subjects who have experienced that phenomenon. "The object of study in phenomenographic research is not the phenomenon being discussed per se [or the relations between researcher and phenomenon, or relations between researcher and subjects], but rather the relation between the subjects and that phenomenon" (p. 12) [55].

This relational position is the reason why researchers should step back in the research process, especially in the data production phase. They are encouraged - although impossible - not to contaminate the data with their own views on the phenomena and not to construct meanings that subjects do not support. 
Phenomenography has an empirical orientation and an inductive nature [21,56,57]. Interviews were used to generate the empirical material that constituted the data in this phenomenographic research. Interpretations and findings were grounded in these raw data [58].

To achieve that, the researcher should read and re-read the data generated many times to become familiar with it [59]. At the beginning, the data may be confusing and indistinguishable. At this point, the researcher should be as open as possible to consider the range of possibilities in interpreting the data. The researcher should also maintain an interactive process with the data, in the sense that readings may give rise to meaning and interpretation and, in reverse mode; meaning and interpretation should be checked against the data to be validated. Hopefully, this process will come to an end with a stable set of categories of description. When possible, the set of categories that were generated should be checked by an independent judge, although some authors argue that this checking is very difficult, since only the constructor of the categories could totally grasp the relationality contained between the categories and the data [60].

Phenomenography is made possible and relevant because the content of the relationship between subject and phenomenon of study is different for different subjects although the phenomenon is identical. The point of departure of phenomenography begins then with the puzzling question "how can people experience differently something that is identical?" This is referred to as the variation theory. People will discern different elements of the phenomenon and the situation. Some will be aware of some relationships; others will be aware of, or discern, other relationships. For some, particular features will be to the fore; for others, different characteristics will blossom [61].

Nevertheless, the variation does not correspond with a one-to-one representation of the subject's description of the phenomena in the sample. The variation is a "limited range of different ways of experiencing", that gives rise to a theory of variation. Moreover, phenomenography does not aim at "generalisations or universal statements" (p. 17) [55] based on this variation. What a phenomenographic researcher is looking for is the range of variation in conceiving or in ways of experiencing a phenomenon within a sample of subjects, which helps in understanding the phenomenon. Unlike research surveys, for example, in phenomenographic research it is not important that some categories have appeared in $\mathrm{x} \%$ of the sample and others in y\% of the sample. In phenomenography, the spectrum of variation is what matters, not the frequency of the categories.

\section{Organizing the Data}

\section{ORGANIZING THE DATA AND THE DATA ANALYSIS}

In this research, data were the interviewees' utterances in the interview process. The data sample consisted of twelve one-to-one interviews conducted with lecturers in three different Universities in the United Kingdom. A number was used to label each interview, for instance, (1). The number is not indicative of any order, be it temporal, gender or importance. The interviewees were primarily from the business schools, but two lectures were from the engineering school. They were interviewed because they taught project management and used simulations.

The main question of the research was how teachers had used simulation-games in their classroom experience? To go deep into the meaning of their responses, some other questions followed: "why do you use simulations"; "what is your role in the simulation?"; "how do you 
support students in the simulation?" I also asked them to recall some happenings in the running of the simulation and remind their actions, thoughts and feelings at the time. Those who had not used simulations and games were questioned the reason why and their overall view about using simulations in management education.

The interviews were recorded and lasted from half an hour to hour and a half. They produced a large stream of data that were listened to and re-listened to many times until I felt familiarized with the data. The analysis was done first to bring relevant themes to the front and then in such a way as to form phenomenographic 'categories of description'.

The analysis of data showed that respondents expressed four qualitatively different conceptions of simulation-games. This is what is called the 'outcome space' of phenomenographic research. Below, the meaning of each one of the four categories of description that were constructed through the analysis of data are briefly related and described. There are also some examples.

\section{The Categories of Description}

The data showed that teachers' experience of using simulations-games in management teaching could be viewed as:

a) Simulation-games as a resource to improve the acquisition of content;

b) Simulation-games as an activity to give students competence in specific skills;

c) Simulation-games as a tool to arise students' engagement;

d) Simulation-games as a means to bear resemblance to reality.

\section{Simulation-games as an additional resource to improve the acquisition of content;}

In this category, teachers experience simulation-games as resources that help students understand the content, which was or would be presented to them in classes. In this way, this category of description compares simulation and games to a form of delivering content, which complements the role of books or lectures.

The relation should be very clear between [the simulation and the content] ... if the game is not related to the topic the students will question ... (1)

Also in this category, there is a sense that the simulation and games used should fit the students' needs in their area of specialization, as described by interviewee (2):

Login Cab [software] is about construction ... Family Life [software] is about magazine ... [but] my students don't work in magazines ... my students aren't on constructions ... where are my students? Where do they need simulations in? (2)

In summary, in this category, simulation-games help teachers to deliver the content of the discipline they are offering.

\section{Simulation-games as an activity to give students competence in specific skills;}

In this category, lectures experience simulation-games as tools that are capable of ignite some students' skills, especially, teamwork and leadership. In other professional fields, as in clinical education, simulation has moved from the province of a few enthusiasts to a mainstream learning modality [62]. In these settings, simulations are largely used to prevent errors and improve patient safety. The Confederation of British Industries (CBI) states that graduates are limited in their employability skills with half of the employers expressing concerns about basic literacy and numeracy skills [13]. It is believed that in simulated rehearsals, mistakes can be made without harming anyone. In the same vein, the data in this research shows that simulation-games may be seen as tools to give students competence in some skills, especially 
team working, decision-making and leadership. One of the interviews states that simulations "encourage things like team-working which is quite important ... and it can [also] help to build commercial awareness" (11). Another interviewee describes how leadership may arouse in the teamwork:
Although I tell them that they can select a leader or not select the leader ... what happens is that [students] who makes sense of it [the simulation] quickly ...become leaders ... and students who are struggling to make sense of it ... just follow the leader ... (7),

and he follows to observe that the process may be the other way round with "one person starting off as a leader ... and someone else takes over ... as they start to understand what's going on ..."

In summary, in this category, simulation-games help to unveil and develop behavioural skills in the participants.

\section{Simulation-games as a tool to arise students' engagement;}

In this category, teachers experience simulation-games as resources to capture students' attention and motivation to their classes. Some teachers struggle to engage students in their classes. Simulation-games may be seen as a kind of social game, where students look for some kind of compensation and amusement to engage in tasks. According to Schwan [63], apud [64] players may be classified in, at least, four different types): impassioned, wanna-be-player, fun player and occasional player. Those who are impassioned may be enthusiastic as they look for a challenge and have high motivation and tolerance to frustration. Wanna-be-players like playing but have low tolerance to frustration. Fun-players treat playing as recreational and occasional-players play for amusement. In summary, simulation-games seem to give students a sense of meaningfulness, because students can see a link between knowledge and what goes on in the real world. That seems to be perceived by teachers, as seen in this quotation,

This [activity] really, I find, engages students ... gets them to really think about ... the different stakeholders in the project which is important ... about what can go wrong in the project ... why can go wrong ... (7)

However, in this category, simulation-games may be seen just as recreational activities to entertain students or given them alternatives to lectures. Asked why students enjoyed simulations, one interviewed answered: "everything that will keep them hands-on ... they would like" (5).

In summary, in this category, simulation-games stimulate participants to take part in the class, and hopefully to learn, especially, if they are having fun doing it.

\section{Simulation-games as a medium to bear resemblance to reality.}

In this category, simulation-games are experienced as resemblance to reality, that is, the activity is an instance of what could be happening in the real world. In some activities, students are given the opportunity to make choices to check how they compromise. For example, in one of these games, students had to deal with limited resources. As one interviewee put it, the students had then to choose, as in life, "whether they're going to share those resources or they're going to be so very selfish" (1). In summary, as interviewee (3) mentioned, in this category, a simulated activity may "become very practical, very realistic, ... very different from an academic way of thinking". 


\section{DISCUSSION}

Before turning to the discussion of the categories of description found in the data, it is important to note that interviewees posed some criticisms to simulations-games. One of the major difficulties some interviewees faced in using simulations or games was the lack of technical support. Some software simulations are still difficult to manage and may present technical problems, unrelated to the subject, which needs technical support to sort them out. This may sometimes be challenging. Interviewee (1), for instance, claimed that the simulation she/he used had "lots of challenges in terms of technological issues".

Another challenging characteristic of simulation-games was the teacher's feeling of losing control over students and over the flux of teaching, what may be uncomfortable. Interviewee (3) observed that in simulation-games "you don't know exactly what's going to happen ... you have to respond ... and sometimes do some quick thinking ... which is a bit of a threat". For him, "only experience may provide a little of comfortable for teachers".

These teacher's challenges in applying the technology may explain the finding of a bi dimensional structure of the outcome space. This bi dimensional structure of the outcome space facilitates the understanding of teachers' experience of simulation and games in management education. The four categories of description shown in section 4.2 were characterized as being composed by two logical dimensions of variation in teachers' experience: instrument and engagement.

In the instrumental dimension, teachers conceive simulation-games as tools to achieve predefined learning goals as they normally do in the traditional lecturing. The first two categories, a) Simulation-games as a resource to improve the acquisition of content, and b) Simulationgames as an activity to give students competence in specific skills are instances of this instrumental orientation.

In the engagement dimension, teachers conceive simulation-games as resources to enable students' participation, in the hope that this participation may bring benefits to students and help them grasp what management is. The two last categories c) Simulation-games as a tool to arise students' engagement, and d) Simulation-games as a means to bear resemblance to reality are examples of this engagement orientation.

Bi dimensional structures of the outcome space have already been used in phenomenographic works, for example, in Åkerlind's research [65]. Åkerlind constructed a bi dimensional outcome space with categories of description describing key aspects of qualitatively different ways of experiencing the phenomenon in question and dimensions of variation, that is, "common themes of expanding awareness running through the categories of description" [56].

This structure of the outcome space identifies two opposing views on the nature of descriptions given by teachers in respect to the meaning of their experience with simulationgames: at one pole, teachers who described their experiences with simulation-games as a 'frustrating experience', independently of this frustration being generated by the method itself or by external constraints as, for example, lack of technical support. Although none of the interviewees opposed vigorously to the method, some were reluctant to the idea of using it. The suggestion is that, although there is a huge effort to the gamification of higher education, there is still a long way to make the method trustful.

At the other pole, there were teachers who described their experience with simulation-games with a sense of meaning; they felt being engaged and self-satisfied by experiencing and using 
the methodology. The method was perceived by these teachers not only as a space for students experience but also as a situation that went beyond the constraints of learning environments; a situation that they could mention as 'realistic' in its own right.

This type of construction of the outcome space of teachers' experience of simulation-games in project management education is important because simulation-games constitute what has been labelled in the literature 'complex learning-teaching arrangements' [66]. Although all learning environments may be considered complex, some learning environments as, for example lectures and case studies, contrive the complexity by delimiting in some ways the content which will be dealt with.

On the other hand, types of complex learning-teaching environments, as is the case of simulation-games, are arrangements that "allow both the simulation of experiences that students might have in the real world and the creation of compelling experiences that cannot normally be experienced directly" (p. 331) [67]. The fabric of this kind of learning environment is intriguing because designers need to take account of two different didactic demands: firstly, they need to filtrate the parts of "reality" which are relevant to the point they are making and, secondly, they must consider the didactic perspective of their view, that is, the consideration of the learning outcomes which should arise out of students' experience.

\section{CONCLUSION}

The four categories of description shown in this research are not exhaustive. Due to the limited nature of the sample, a full detailed description of teachers' experience of simulation-games may not have been achieved. Nevertheless, the sample showed a very distinctive dual nature of teachers' experience of simulation-games. On the one hand, there are those who use simulation-games as tools to pursue predetermined learning outcomes. The simulation-game is a means to transfer these learning goals, whichever they are, to students.

On the other hand, there are those who use simulation-games as an engagement tool. The student engagement is a critical priority for some teachers as it arises motivation and participation. Teaching and learning is easier in such environment.

In summary, simulation-games have gained space in management educational environments, despite the many challenges they still may have to overcome.

\section{ACKNOWLEDGEMENTS}

This research study was supported by Coordenação de Aperfeiçoamento de Pessoal de Nível Superior - CAPES, Brazil [Processo BEX 0086/15-0]

\section{References}

Dewey, J. (1910,1991). How We Think. New York, Prometheus Books.

Knowles, M. (1980). The Modern Practice of Adult Education: from pedagogy to andragogy. Chicago, Follett Pub. Co.

Knowles, M. (2005). The Adult Learner: the definitive classic in adult education and human resource development. Houston, Tex., Gulf Pub. Co.

Galbraith, M. (2004). The teacher of adults. In Galbraith, M. (Ed). Adult learning methods: a guide for effective instruction. Krieger Publishing, Florida, USA.

Heinzen, T. E.; Gordon, M. S. et al. (2015). A parallel universe: psychological science in the language of game design. In Reiners, T. and Wood, L. C. (Eds). Gamification in Education and Business. Springer, New York. 
Kotini, I.; Tzelepi, S. (2015). A gamification-based framework for developing learning activities of computational thinking. In Reiners, T. and Wood, L. C. (Eds). Gamification in Education and Business. Springer, New York.

Kapp, K. M. (2012). The gamification of learning and instruction: game-based methods and strategies for training and education. Pfeiffer, San Francisco, USA.

Telukunta, S., Kota, S., Potti, S., Shashank, H., and Reddy, T. (2014) 'StrateJect: An Interactive Game for Project Management Experiential Learning'. PMPC, 2014.

Martin, A. (2000). A Simulation Engine for custom project management education. International Journal of Project Management. 18.

Pant, I.; Baroudi, B. (2008). Project management education: the human skills imperative. International Journal of Project Management. 26, 124-128.

Wood, L. C.; Reiners, T. (2015). Storytelling to Immersive Learners in an Authentic virtual training environment. In Reiners, T. and Wood, L. C. (Eds). Gamification in Education and Business. Springer, New York.

CBI (2011) Building for Growth: business priorities for education and skills -education and skills survey 2011. Downloaded from http://www.ucml.ac.uk/sites/default/files/ shapingthefuture/101/cbi_edi_education__skills_survey_2011.pdf in 05/10/2016.

Prosser, M. and K. Trigwell (1999). Understanding Learning and Teaching: the experience in higher education. Buckingham/Philadelphia, SRHE \& Open University Press.

Marzano, R. J. and Marzano, J. S. (2010). The inner game of teaching. In Marzano, R. J. (Ed). On the Excelence in Teaching. Solution Tree, USA.

Trigwell, K., M. Prosser, et al. (1994). Qualitative Differences in Approaches to Teaching First Year University Science. Higher Education. 27: 75-84.

Dall'Alba, G. (1991). Foreshadowing Conceptions of Teaching. Research and Development in Higher Education. 13: 293-7.

Martin, E. and M. Balla (1991). Conceptions of Teaching and Implications for Learning. Research and Development in Higher Education. 13: 298-304.

Samuelowicz, K. and J. Bain (1992). Conceptions of Teaching Held by Teachers. Higher Education. 24: 93-112.

[20] Kember, D. (1997). A Reconceptualisation of the Research into University Academics' Conceptions of Teaching. Learning and Instruction. 7(3): 255-277.

Åkerlind, G. (2005). Variation and Commonality in Phenomenographic Research Methods. Higher Education Research \& Development. 24(4): 321-334.

Lameras, P., Levy, P., Paraskakis, I. and Webber, S. (2012). Blended university teaching using virtual learning environments: conceptions and approaches. Instructional Science. volume 40 (1): 141-157.

Lameras, P., Paraskakis, I. and Levy, P. (2008). Conceptions of teaching and learning using virtual learning environments: preliminary findings from a phenomenographic inquiry. Paper presented at the Sixth International Conference on Networked Learning, Halkidiki, Greece.

Kolb, D. A., Rubin, I. M., McIntyre, J. M. (1974). Organizational Psychology: a book of readings. $2^{\text {nd }}$ edition. Englewood Cliffs, N. J.: Prentice-Hall.

Chamorro-Remuzic, T. Furnham, A. (2008). Personality, intelligence and approaches to learning as predictors of academic performance. Personality and Individual Differences. 44, 1596-1603.

Furnham, A.; Monsen, J. (2009). Personality traits and intelligence predict academic school grades. Personality and Individual Differences. 19, 28-33.

Lave, J. and E. Wenger (1991). Situated Learning: legitimate peripheral participation. Cambridge, Cambridge University Press.

Lave, J. and E. Wenger (1999). Legitimate Peripheral Participation in Communities of Practice: learning and knowledge. R. McCormick and C. Paechter. London, Paul Chapman.

Fox, S. (1997). From Management Education and Development to the Study of Management Learning.

Management Learning: integrating perspectives in theory and practice. J. Burgoyne and M. Reynolds.

London/Thousand Oaks/New Delhi, Sage Publications.

Bates, B. (2004). Game Design. Thomson, USA. 
Baudrillard, J. (1983). Simulations. New York: Semiotext [e].

Akilli, G. K. (2007). Games and Simulations: a new approach in education? In Gibson, D. et al. (Eds). Games and Simulations in Online Learning: research and development frameworks. Information Science Publishing, Hershey.

Robinson, S. (2004). Simulation: the practice of model development and use. John Wiley \&Sons, West Sussex, England.

Kapp, K. M.; Blair, L.; Mesch, R. (2014). The Gamification of Learning and Instruction Fieldbook: ideas into practice. Wiley, San Francisco, CA.

Project Management Institute. (2004). A Guide to the Project Management Body of Knowledge (PMBOK guide). Newtown Square, Pa: Project Management Institute.

Turner, J.R. (2014). The Handbook of Project-Based Management: leading strategic change in organizations. McGraw-Hill, New York.

Lock, D. (2013). Project Management. Gower Publishing Limited, Surrey, UK.

Horine, G. (2005). Absolute Beginner's Guide to Project Management. Indianapolis. Que.

Larson, E. W. \& Gray, C. F. (2011). Project Management: the managerial process. McGaw-Hill, New York.

Seager, W.; Ruskov, M. et al. (2010). Eliciting and Modelling Expertise for Serious Games Design. Entertainment Computing. 2, 75-80.

Bohn, A. \& Lynch-Caris, T. (2013). Getting into the Game: increase project management skills via roleplaying simulations. Industrial Engineer.

Sáenz, M. J. et al. (2004). Simulation Laboratory for Virtual Negotiation on Project Management. SIG Experimental Learning Workshop.

Cleland, D. I.; Ireland, L.R. (2010). Project Manager's Portable Handbook. McGraw-Hill, New York.

Rounds, J. L. \&. Alli. (1986). Project Management Simulation Training Game. Journal of Management in Engineering. Vol. 2, No. 4.

Egenfeldt-Nielson, S. (2007). Educational Potential of Computer Games. Continuum International Publishing Group, New York.

Weterman, L. et al. (2011). Simulations and Industry Mentors as a Pathway to Learning 'near world' Project Management. $8^{\text {th }}$ Project Management Australia Conference. Sydney, Australia.

Bonazzi, R. et al. (2012). Analysis of Serious Games Implementation for Project Management Courses. In M. de Marco et al. (eds.), Information Systems: crossroads for organization, management accounting and engineering. Springer-Verlag, Berlin, Heiderlberg.

Bell, Andrew (2016). The Development of a Conceptual Framework for Simulations in Project Management Education. Unpublished PhD Thesis. Coventry: Coventry University.

Caulfield, C.; Maj, S.P. \& al. (2012). Shall we Play a Game? Modern Applied Science. Vol. 6, No. 1.

Marton, F. \& S. Booth (1997). Learning and Awareness. New Jersey, Lawrence Erlbaum Associates.

Cousin, G. (2009). Researching Learning in Higher Education: an introduction to contemporary methods and approaches. Routledge, New York.

Dall'Alba, G. (2000). Reflections on Some Faces of Phenomenography. Phenomenography. J. A. Bowden and E. Walsh. Melbourne, RMIT University Press.

Marton, F. (1981). Phenomenography - Describing Conceptions of the World Around us. Instructional Science. 10: $177-200$.

Uljens, M. (1996). On the Philosophical Foundations of Phenomenography. In: G. Dall'Alba and B. Hasselgren (Eds), Reflections of Phenomenography: toward a methodology. Göteborg, Acta Universitatis Gothorburgensis.

Bowden, J. (2005). Reflections on the Phenomenographic Team Research Process. Doing Developmental Phenomenography. J. A. Bowden. Melbourne, RMIT University Press: 11-31. 
Åkerlind, G. (2002). Principles and Practice in Phenomenographic Research. Proceedings of the International Symposium on Current Issues in Phenomenography. Canberra, Australia.

Bowden, J. and P. Green, Eds. (2005). Doing Developmental Phenomenography. Melbourne, RMIT University Press.

Green, P. (2005). A Rigorous Journey into Phenomenography: from a Naturalistic Inquirer Viewpoint. Doing Developmental Phenomenography. J. Bowden and P. Green. Melbourne, RMIT University Press.

Barnacle, R. (2005). Interpreting Interpretation: a Phenomenological Perspective on Phenomenography. Doing Developmental Phenomenography. J. Bowden and P. Green. Melbourne, RMIT University Press.

Sandberg, J. (1996). Are Phenomenographic Results Reliable? In: G. Dall'Alba and B. Hasselgren (Eds), Reflections of Phenomenography: toward a methodology. Göteborg, Acta Universitatis Gothorburgensis.

Dunkin, R. (2000). Using Phenomenography to Study Organisational Change. Phenomenography. J. A. Bowden and E. Walsh. Melbourne, RMIT Publishing: 137-150.

NHS England (2016). Retrieved from http://www.faculty.londondeanery.ac.uk/e-learning/using-simulation-inclinical-education. In 05/10/2016.

Schwan. S. (2006). Game based learning. Retrieved from www.e-teaching.org.

Denholm, J.; Dunwell, I. et al. (2015). The development and assessment of a team-based management game. In Reiners, T. and Wood, L. C. (Eds). Gamification in Education and Business. Springer, New York.

Åkerlind, G. (2003). Growing and Developing as a University Teacher - Variation in Meaning. Studies in Higher Education. 28: 375-390.

Ertl, H. and P. Sloane (2004). A Comparison of VET Structures in Germany and England: Contexts of Complex Teaching-Learning Arrangements. New Approaches to Vocational Education in Europe. R. H. Mulder and P. F. E. Sloane. Oxford, Symposium Books.

Winn, W. (2002). Current Trends in Educational Technology Research: The Study of Learning Environments. Educational Psychology Review. 14(3): 331:351.

De Freitas, S. \& Martin, O. (2007) How can exploratory learning with games and simulations within the curriculum be most effectively evaluated? Computers in Education. volume 46 (3): 249-264. 